\title{
Comparison of Field Olfactometers in a Controlled Chamber using Hydrogen Sulfide as the Test Odorant
}

\author{
Authored by: \\ Michael A. McGinley, P.E. \\ St. Croix Sensory, Inc. \\ $\&$ \\ Charles M. McGinley, P.E. \\ St. Croix Sensory, Inc.
}

\author{
Presented at the \\ International Water Association \\ 2nd International Conference on Odour and VOCs \\ Singapore: 14-17 September 2003. \\ Also in Water Sc. Technol. 2004, 50(4): 75-82
}

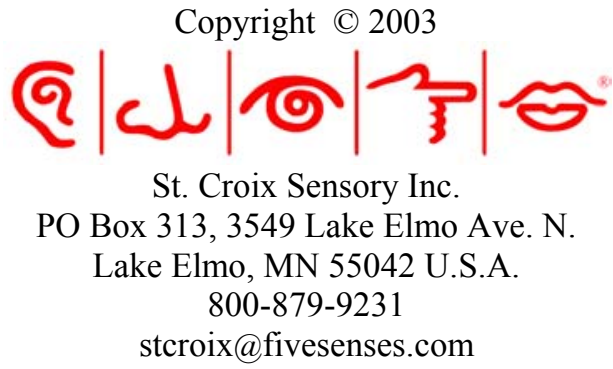




\title{
Comparison of Field Olfactometers in a Controlled Chamber using Hydrogen Sulfide as the Test Odorant
}

\author{
M.A. McGinley*, C.M. McGinley* \\ * St. Croix Sensory, Inc., P.O. Box 313, 3549 Lake Elmo Ave. N., Lake Elmo, MN, 55042, USA \\ (E-mail:mike@fivesenses.com; cmcginley@fivesenses.com)
}

\begin{abstract}
A standard method for measuring and quantifying odour in the ambient air utilizes a portable odour detecting and measuring device known as a field olfactometer (U.S. Public Health Service Project Grant A-58-541). The field olfactometer dynamically dilutes the ambient air with carbon-filtered air in distinct ratios known as "Dilutionsto-Threshold" dilution factors (D/T's), i.e. 2, 4, 7, 15, etc. Thirteen U.S. states and several cities in North America currently utilize field olfactometry as a key component of determining compliance to odour regulations and ordinances.
\end{abstract}

A controlled environmental chamber was utilized with hydrogen sulfide as the known test odorant. A hydrogen sulfide environment was created in this controlled chamber using an Advanced Calibration Designs, Inc. Cal2000 Hydrogen Sulfide Generator. The hydrogen sulfide concentration inside the chamber was monitored using an Arizona Instruments, Inc. Jerome Model $631 \mathrm{H}_{2} \mathrm{~S}$ Analyzer.

When the environmental chamber reached a desired test concentration, test operators entered the chamber. The dilution-to-threshold odour concentration was measured using a Nasal Ranger Field Olfactometer (St. Croix Sensory, Inc.) and a Barneby Sutcliffe Corp. Scentometer. The actual hydrogen sulfide concentration was also measured at the location in the room where the operators were standing while using the two types of field olfactometers.

This paper presents a correlation between dilution-to-threshold values $(\mathrm{D} / \mathrm{T})$ and hydrogen sulfide ambient concentration. For example, a D/T of 7 corresponds to ambient $\mathrm{H}_{2} \mathrm{~S}$ concentrations of 4-11 ppb. During this study, no significant difference was found between results obtained using the Scentometer or the Nasal Ranger $(\mathrm{r}=0.82)$. Also, no significant difference was found between results of multiple Nasal Ranger users $(\mathrm{p}=0.309)$. The field olfactometers yielded hydrogen sulfide thresholds of 0.5-2.0ppb. Laboratory olfactometry yielded comparable thresholds of 0.45-0.9 ppb. These thresholds are consistent with published values.

\section{Keywords}

Ambient odour measurement; detection threshold; dilution-to-threshold; field olfactometer; odour concentration; olfactometer

\section{INTRODUCTION}

Community odours remain at the top of air pollution complaints to regulators and government bodies internationally. Ambient air holds a mixture of odorous chemicals from everyday activities of industrial and commercial enterprises. When air quality is compromised with odours, effective study, investigation, and enforcement requires that odours be measured using standardized methods that are dependable, reproducible, objective, and quantitative. 
Field olfactometry can be used as a proactive monitoring or enforcement tool for odour measurement at property lines and in the neighboring community. The quantification of ambient odours is typically needed for the following purposes:

1. Monitoring daily operations (management performance evaluations);

2. Comparison of operating practices (evaluating alternatives);

3. Documenting specific events or episodes (defensible, credible evidence);

4. Monitoring compliance (i.e. compliance assurance permits);

5. Determination of compliance (i.e. permit renewal);

6. Determination of facility status (i.e. baseline data for expansion planning);

7. Investigation of odour control effectiveness (i.e. scientific testing);

8. Verification of odour dispersion modeling (i.e. model calibration);

9. Determination of specific odour sources (i.e. investigation of complaints);

10. Verification of complaints (i.e. notice of violation).

Field olfactometry has the following key advantages over laboratory olfactometry for measurement of ambient odours.

1. Lower method detection limit (most laboratory olfactometers have a method detection limit of 5-10 dilutions);

2. Immediate results (Laboratory results can take 1-5 days to receive a report);

3. Eliminates concern for deterioration of odour in the sample bag; and

4. Low per sample cost.

This study focused on the use of field olfactometers. A series of hydrogen sulfide concentrations were tested in an environmental chamber. Data will be presented which will compare the results obtained using two commercially available field olfactometers. Data will also show correlation between hydrogen sulfide concentration and the dilutionto-threshold values obtained by the field olfactometer tests.

\section{FIELD OLFACTOMETRY}

In 1958, 1959, and 1960 the U.S. Public Health Service sponsored the development of an instrument and procedure for field (ambient) odour measurement through Project Grants A-58-541, A-59-541, and A-60-541. The instrument, originally manufactured by Barnebey-Chaney Company and subsequently manufactured by Barnebey Sutcliffe Corporation is known as a "Scentometer" (Huey, et al., 1960).

A field olfactometer dynamically dilutes the ambient air with carbon-filtered air in discrete "dilution ratios." The U.S. Public Health Service method defined the dilution ratio (dilution factor) as "Dilution-to-threshold," D/T. The Dilution-to-threshold is a measure of the number of dilutions needed to dilute the odour to the threshold. The method for calculating the "Dilution-to-threshold" $(\mathrm{D} / \mathrm{T})$ is:

Dilution Ratio $=$ Volume of Carbon-Filtered Air / Volume of Odorous Air 
Figure 1 is a block diagram of a field olfactometer illustrating the flow of ambient air, carbon-filtered air, and the diluted odour mixture.

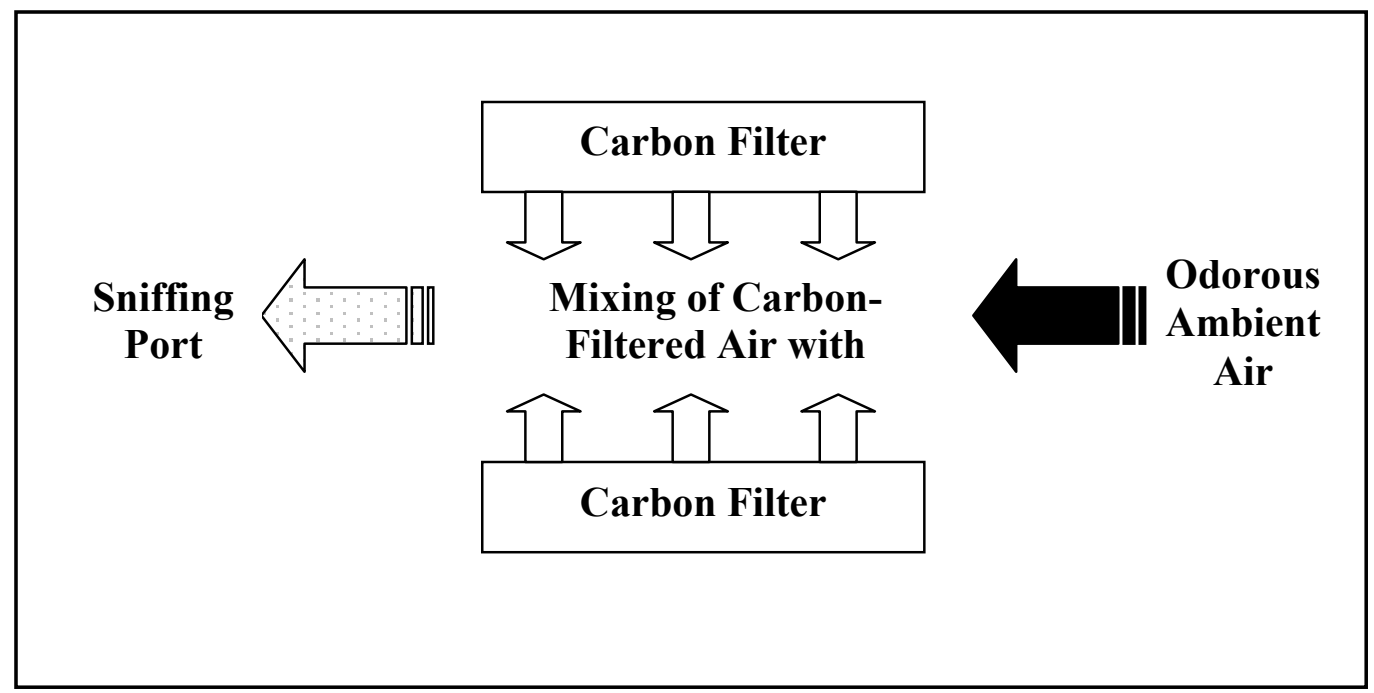

Figure 1. Block diagram of field olfactometer air flow.

\section{Scentometer}

The Barnebey Sutcliffe Corporation Scentometer is a rectangular, clear plastic box $(15.25 \mathrm{~cm} \times 12.7 \mathrm{~cm} \times 6.2 \mathrm{~cm})$ containing two activated carbon beds (see Figure 2). The box contains two $1 / 2$ " diameter air inlets to the activated carbon beds (one on top and one on the bottom of the box). There are six odorous air inlet holes on one end of the box for six different $\mathrm{D} / \mathrm{T}$ values $(2,7,15,31,170$, and 350$)$. The opposite end of the box contains two glass nostril tubes for sniffing. Figure 2 shows a photo of a Scentometer.

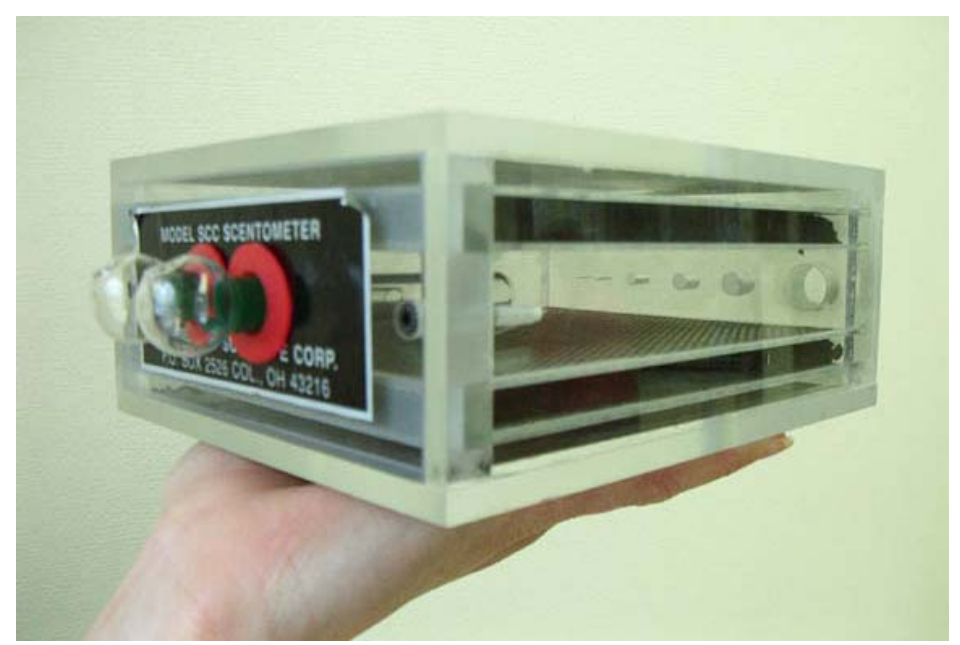

Figure 2. The Scentometer Field Olfactometer (Barnebey Sutcliffe Corp.). Note the two glass nostril ports to the left and the series of orifice holes at the back of the unit to the right in this photo. 


\section{Nasal Ranger Field Olfactometer}

The St. Croix Sensory - Nasal Ranger Field Olfactometer operates based on the same principles as the original Scentometer. Figure 3 is a photo of a Nasal Ranger. Carbonfiltered air is supplied through two replaceable carbon cartridges. An orifice selector dial on the Nasal Ranger contains six odorous air inlet orifices for six different $\mathrm{D} / \mathrm{T}$ values (2, $4,7,15,30$, and 60$)$. The dial contains six "blank" positions (100\% carbon-filtered air) alternating with the $\mathrm{D} / \mathrm{T}$ orifices. The dial is replaceable for other $\mathrm{D} / \mathrm{T}$ series (e.g. 60, $100,200,300,400,500)$.

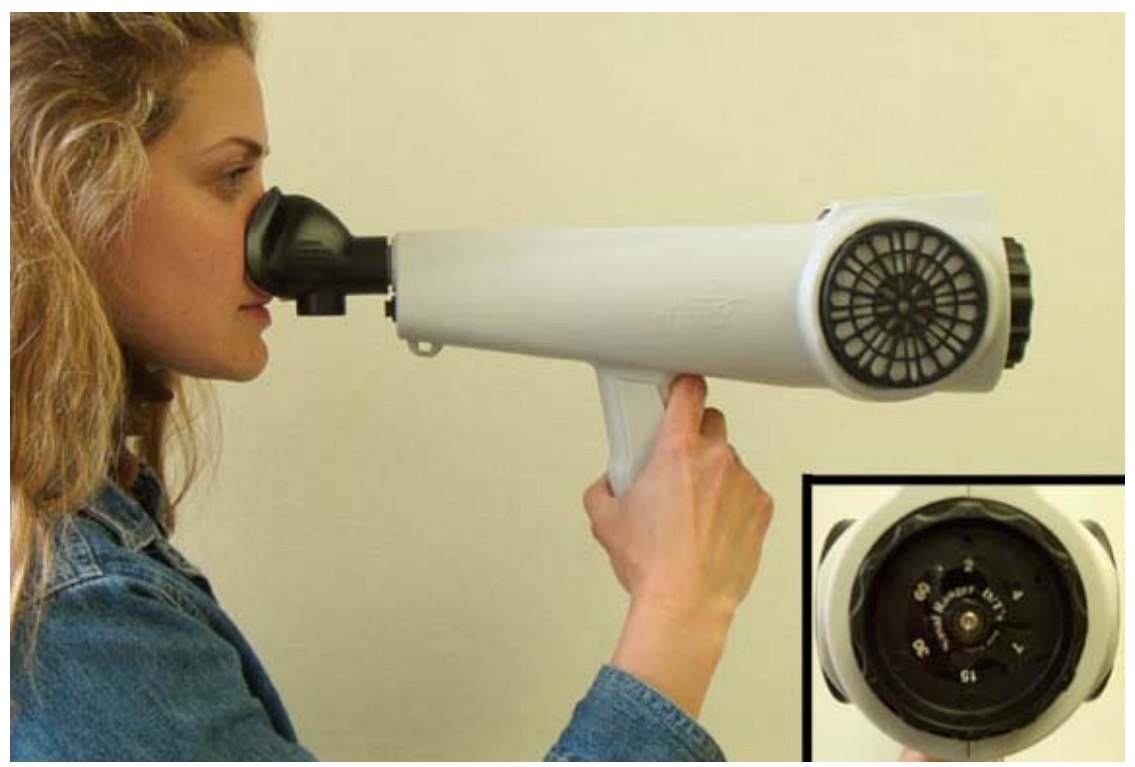

Figure 3. The Nasal Ranger ${ }^{\circledR}$ Field Olfactometer (St. Croix Sensory, Inc.). The inset picture shows a close-up of the orifice dial, which is located to the right side of the Nasal Ranger in this photo.

The diluted odorous air is sniffed through an ergonomically designed nasal mask, which is constructed of a carbon fiber/epoxy blend with a fluoropolymer (Teflon-like) coating. A check valve is placed in both the inhalation end and exhalation outlet of the nasal mask in order to control the direction of airflow while using the Nasal Ranger.

The Nasal Ranger is designed with an airflow sensor that measures the sniffing flow rate through the field olfactometer. The measured flow is continually compared to design specifications and feedback is provided to the user through LED's mounted on the top of the unit. The user must sniff at a rate where the LED's show the total airflow is in a Target range (nominal 16-20 LPM). This feedback loop standardizes the sniffing rate for all users of this field olfactometer and allows for certified traceable calibration of the Nasal Ranger. 


\section{METHODS}

\section{Hydrogen Sulfide Feed}

Hydrogen Sulfide $\left(\mathrm{H}_{2} \mathrm{~S}\right)$ was selected as the test odorant for this study due to the availability of a reliable, continuous hydrogen sulfide generator and a hand-held hydrogen sulfide detector. An Advanced Calibration Designs, Inc. (ADC) Cal2000 Hydrogen Sulfide Generator was used to produce the constant feed of $\mathrm{H}_{2} \mathrm{~S}$. This generator, shown in Figure 4, utilizes an electrochemical cell to produce a reliable and continuous feed of $\mathrm{H}_{2} \mathrm{~S}$ with an allowable feed rate ranging from 0.2-LPM to 1.0-LPM and a concentration range from 0.5 parts per million (ppm) to $50 \mathrm{ppm}$.

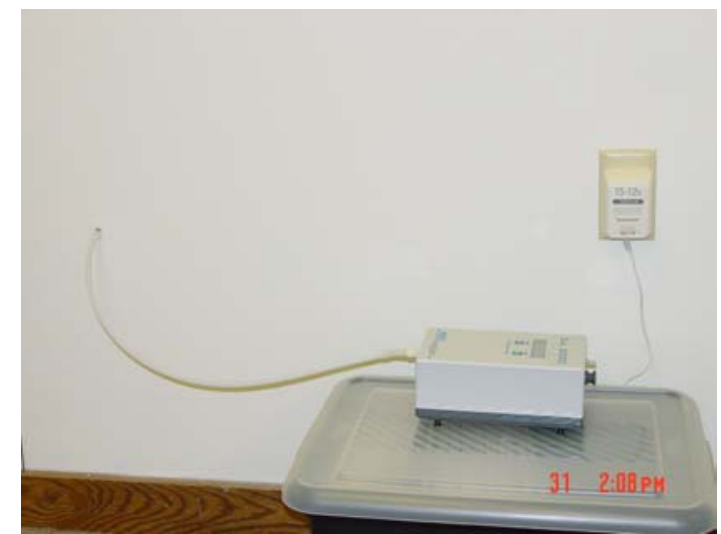

Figure 4. Advanced Calibration Designs, Inc. Cal2000 Hydrogen Sulfide Gas Generator. The gas feed line travels from the generator through the chamber wall to the injection point.

The Cal2000 $\mathrm{H}_{2} \mathrm{~S}$ Generator was placed outside the chamber where laboratory air served as the feed air. The generated $\mathrm{H}_{2} \mathrm{~S}$ was fed to the chamber through 1/4" Teflon Tubing.

\section{Hydrogen Sulfide Measurement}

An Arizona Instrument, Inc. (AZI) Jerome Model $631 \mathrm{H}_{2} \mathrm{~S}$ hand-held analyzer was used to measure the $\mathrm{H}_{2} \mathrm{~S}$ concentration in the chamber with a lower detection limit of 0.001 ppm (1 ppb). The AZI "Jerome Meter", shown in Figure 5, utilizes an in-line sample pump to pull the air sample across a gold film. The change in resistance of this gold film is related to the concentration of hydrogen sulfide in the air.

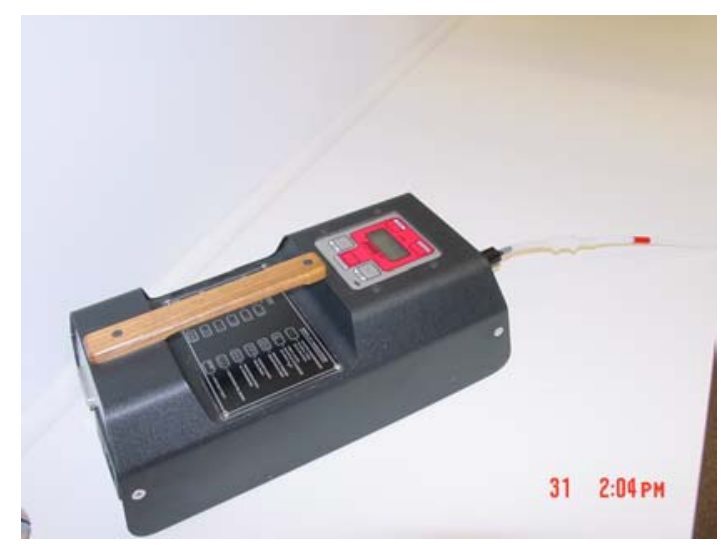

Figure 5. Arizona Instruments, Inc. Jerome Model 631 H2S Analyzer. 


\section{The Test Chamber}

The controlled chamber located at the St. Croix Sensory, Inc. laboratory (Lake Elmo, $\mathrm{MN}$ ) has dimensions of $3.75 \mathrm{~m} \times 4.7 \mathrm{~m} \times 2.7 \mathrm{~m}\left(47.3 \mathrm{~m}^{3}\right)$. This chamber has four walls and a ceiling with 1" dry-wall coated with several layers of non-porous paint. The floor is covered with a low pile carpet. For this study, several standard room fans were used to mix the chamber air. No fresh air was supplied to the chamber during the test, i.e. zero air changes per hour, except minimal amounts as participants entered the chamber through the main door.

The $\mathrm{H}_{2} \mathrm{~S}$ was introduced to the chamber at the center of one wall, 1-meter off the floor. Figure 6 is a top view diagram of the test chamber including the $\mathrm{H}_{2} \mathrm{~S}$ feed location, circulation fans, the main $\mathrm{H}_{2} \mathrm{~S}$ monitoring location, and field olfactometer testing locations.

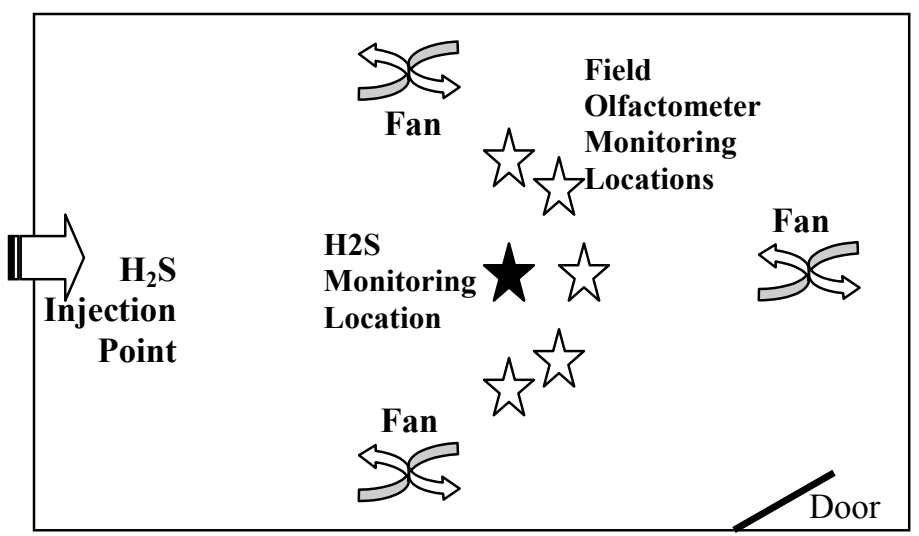

Figure 6. Top view of Test Chamber showing Hydrogen Sulfide injection point, circulation fans, and monitoring locations.

A TSI, Inc. Q-Track Pro Indoor Air Quality Meter was used to monitor temperature, relative humidity, and Carbon Dioxide in the chamber.

\section{Odour Quantification}

Trained and experienced users of field olfactometers were utilized for this study. Up to four observers used separate Nasal Ranger Field Olfactometers and one observer used a Scentometer Field Olfactometer. All field olfactometer observations were made in the blind.

The hydrogen sulfide tracer gas feed was started and the $\mathrm{H}_{2} \mathrm{~S}$ concentration was continuously monitored at the center of the chamber. As the concentration of $\mathrm{H}_{2} \mathrm{~S}$ increased, the odour observers periodically entered the chamber and used a field olfactometer to determine the $\mathrm{D} / \mathrm{T}$ of the odour. Three test trials were performed for this study: 
1. $\mathrm{H}_{2} \mathrm{~S}$ feed concentration of $10 \mathrm{ppm}$ at 1-LPM; two Nasal Ranger users and one Scentometer user.

2. $\mathrm{H}_{2} \mathrm{~S}$ feed concentration of $25 \mathrm{ppm}$ at 1-LPM; four Nasal Ranger users and one Scentometer user.

3. $\mathrm{H}_{2} \mathrm{~S}$ feed concentration of $25 \mathrm{ppm}$ at 1-LPM; two Nasal Ranger users and one Scentometer user.

The Jerome hydrogen sulfide meter was used to periodically check $\mathrm{H}_{2} \mathrm{~S}$ concentrations throughout the room, i.e. wall to wall and floor to ceiling, to confirm the $\mathrm{H}_{2} \mathrm{~S}$ concentration in the chamber was homogeneous.

During trial 3, three grab air samples were collected in Tedlar bags for analysis in the odour laboratory at St. Croix Sensory. All laboratory olfactometry was conducted following odour testing standards ASTM International E679 and EN13725 (ASTM, 1991; CEN 2003).

Throughout the study, the following parameters were recorded: 1) hydrogen sulfide concentration inside the chamber, 2) D/T values obtained by each observer, and 3) recognition threshold values obtained by laboratory olfactometry in trial \#3.

\section{RESULTS AND DISCUSSION}

Figure 7 shows the curves of hydrogen sulfide concentration versus time for all three tests. For the two tests with a feed of $25 \mathrm{ppm}$ at 1-LPM, the $\mathrm{H}_{2} \mathrm{~S}$ concentration profiles were similar. Periodic checks of the $\mathrm{H}_{2} \mathrm{~S}$ concentration from wall to wall and from floor to ceiling were all within $\pm 1.5 \mathrm{ppb}$, confirming the chamber was well mixed.

\section{Dilution-to-Threshold Relationship to Hydrogen Sulfide Concentration}

Figure 8 is a graph of $\mathrm{D} / \mathrm{T}$ values determined by the observers at various $\mathrm{H}_{2} \mathrm{~S}$ concentrations inside the chamber. All observations throughout the three trials are represented in this figure. The data shows consistency between field olfactometers and users. The figure can be summarized by the following general "rules of thumb":

> 2-4 ppb $\mathrm{H}_{2} \mathrm{~S}$ yields a $\mathrm{D} / \mathrm{T}$ of 2

$>4-5 \mathrm{ppb} \mathrm{H}_{2} \mathrm{~S}$ yields a $\mathrm{D} / \mathrm{T}$ of 4

$>4-11 \mathrm{ppb}_{2} \mathrm{~S}$ yields a $\mathrm{D} / \mathrm{T}$ of 7

> 11-17 $\mathrm{ppb}_{2} \mathrm{~S}$ yields a $\mathrm{D} / \mathrm{T}$ of 15

$>17-28 \mathrm{ppb} \mathrm{H}_{2} \mathrm{~S}$ yields a $\mathrm{D} / \mathrm{T}$ of 30

> 28-40+ $\mathrm{ppb}_{2} \mathrm{~S}$ yields a $\mathrm{D} / \mathrm{T}$ of 60

It should be noted that all trials were complete before the $\mathrm{H}_{2} \mathrm{~S}$ concentration reach $45 \mathrm{ppb}$. It is expected that $\mathrm{H}_{2} \mathrm{~S}$ concentrations higher than $40 \mathrm{ppb}$ will also yield a D/T of 60 .

Of the eight observation points which deviated from these "rules of thumb", five were observations using a Scentometer. These five observations were lower D/T's than were 


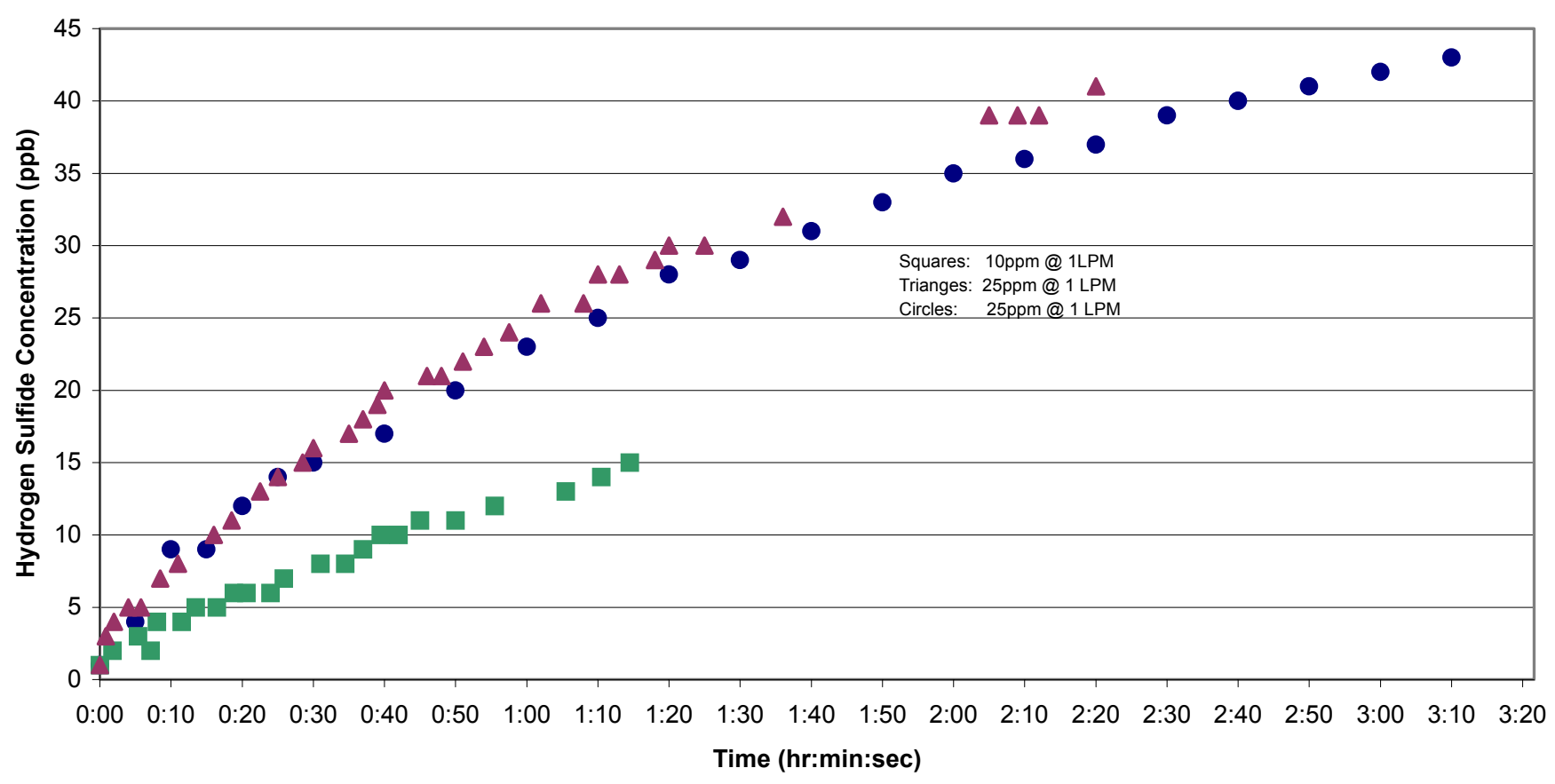

Figure 7. Hydrogen Sulfide Concentration measured at the center of the test chamber during three trials. The first trial was run at 1-LPM with a 10-ppm feed of $\mathrm{H}_{2} \mathrm{~S}$. The second and third trials were run at 1-LPM with a 25-ppm feed.

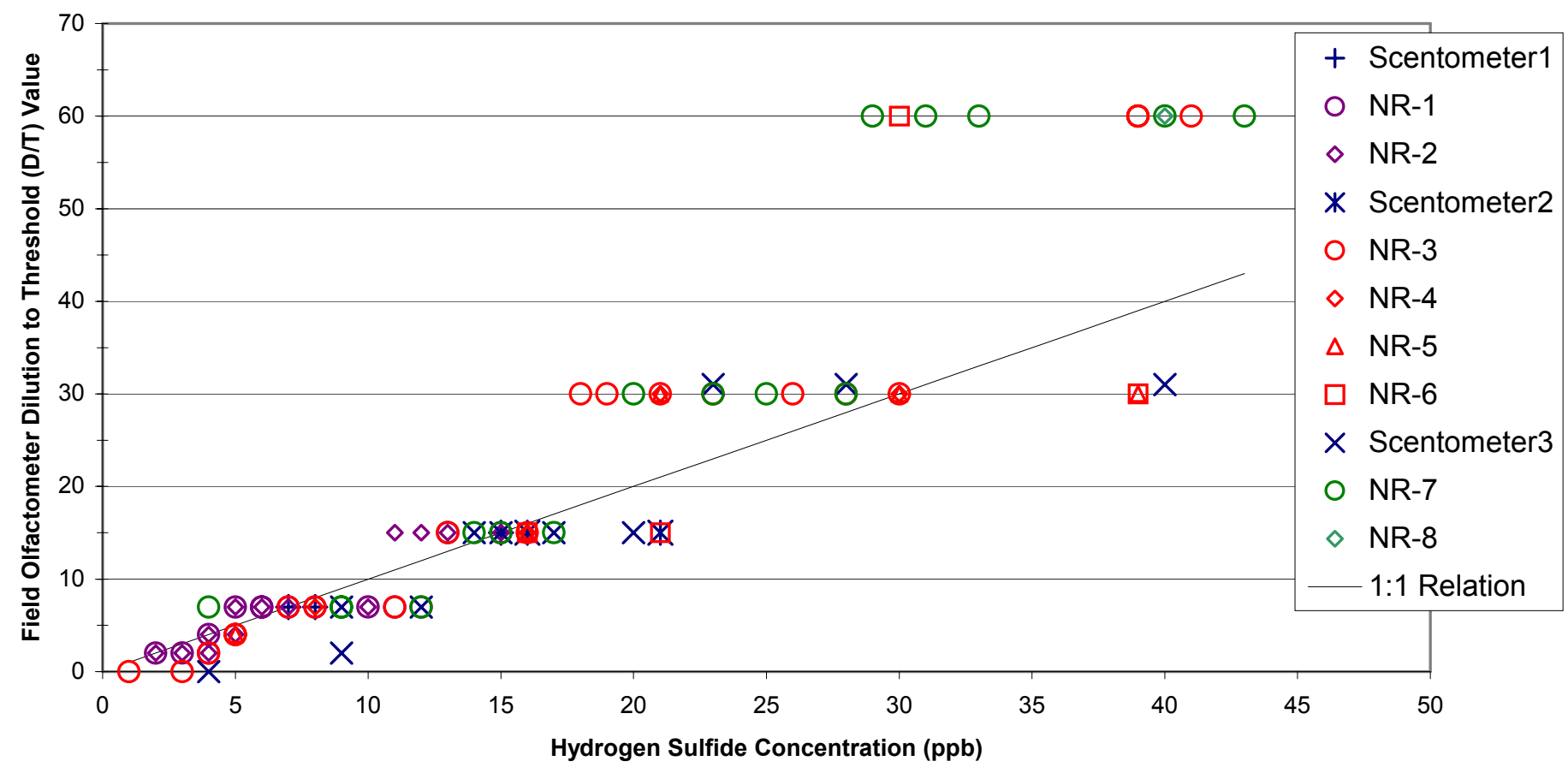

Figure 8. Observed Dilution-to-Threshold (D/T) values determined as the concentration of hydrogen sulfide was increased in a environmental chamber. The data points represent observations made during three trials. Observations were made by one Scentometer user and four Nasal Ranger users. 
recorded by the other observers with Nasal Rangers. Specifically, note that while Nasal Ranger readings were $\mathrm{D} / \mathrm{T}=60$, the Scentometer had readings of 31 since it does not have a $\mathrm{D} / \mathrm{T}=60$ position.

A statistical review was performed to compare responses by the Scentometer user to those responses by the Nasal Ranger users. There were sixteen observation points where both Scentometer and Nasal Ranger readings were recorded by different observers. A student t-test performed shows no significant difference between these observations at a 95\% confidence level $(p=0.06)$. Further, the comparison had a Pearson's Correlation Coefficient [r] of 0.82 .

Comparison of observations made by multiple Nasal Ranger users at the same observation points was performed with an analysis of variance (ANOVA). Results of this analysis at the $95 \%$ confidence level show no significant difference between users over the range of observations $(\mathrm{p}=0.309)$.

\section{Hydrogen Sulfide Threshold Concentration}

The odour threshold concentration of hydrogen sulfide can be calculated using the observed dilution-to-threshold $(\mathrm{D} / \mathrm{T})$ results. The chamber concentration $(\mathrm{ppb})$ divided by the $\mathrm{D} / \mathrm{T}$ value yields the $\mathrm{H}_{2} \mathrm{~S}$ threshold concentration (ppb). Figure 9 displays the calculated odour thresholds versus the chamber concentration.

Figure 9 shows that $98 \%$ of observations had a calculated $\mathrm{H}_{2} \mathrm{~S}$ threshold between $0.5-2.0$ ppb. There was only one observation point outside this range. At a chamber concentration of $9 \mathrm{ppb}$, there was one comparatively low Scentometer reading that was only $\mathrm{D} / \mathrm{T}=2$. This yielded an odour threshold of $4.5 \mathrm{ppb}$. Less than $10 \%$ of observations had a calculated $\mathrm{H}_{2} \mathrm{~S}$ threshold greater than $1.5 \mathrm{ppb}$.

These calculated odour thresholds follow a set of six increasing trendlines. Note that these six linear curves are directly related to the step-wise increase in observed $\mathrm{D} / \mathrm{T}$ values on the field olfactometers (D/T values of 2, 4, 7, 15, 30, and 60). Figure 10 has six trendlines superimposed onto the data points showing the results related to each discrete D/T position on the Scentometer and Nasal Ranger field olfactometers.

It is important to define the threshold determined using a field olfactometer. A detection threshold is defined as that point where the diluted odour sample just becomes different from the odour-free air. A recognition threshold is the point where the diluted odour is different from the odour free air and has a discernable character. For field olfactometers, it is more appropriate to consider the dilution-to-threshold value a recognition threshold. Outside the controlled conditions of a laboratory, an observer will usually need to notice an odour character before confidently declaring the $\mathrm{D} / \mathrm{T}$ value of the odour.

The American Industrial Hygiene Association document titled, "Odor Thresholds for Chemicals with Established Occupational Health Standards" has the detection threshold of $\mathrm{H}_{2} \mathrm{~S}$ listed as $0.5 \mathrm{ppb}$ and a recognition threshold of $5 \mathrm{ppb}$ (AIHA, 1989; WEF, 1995). 


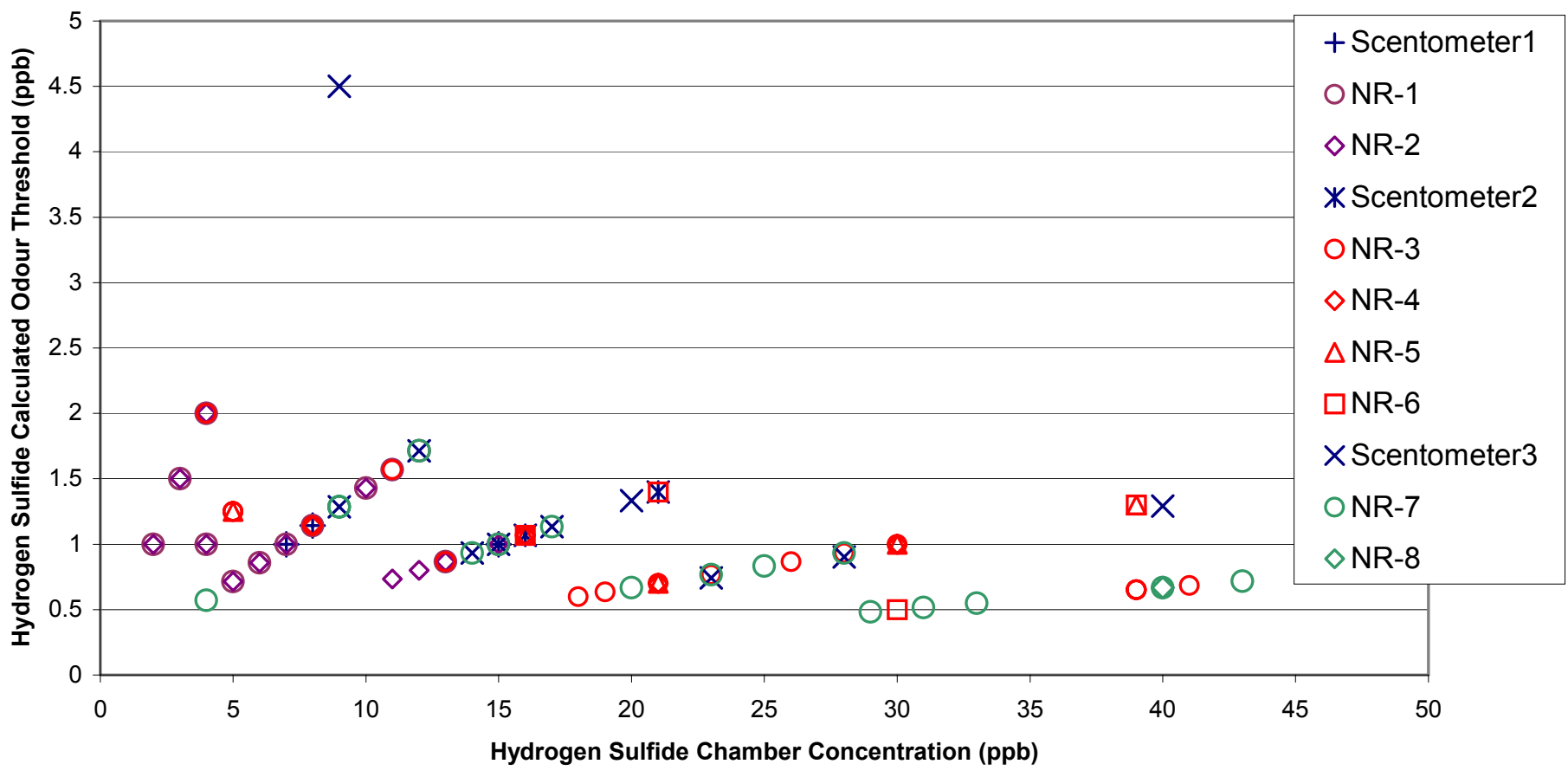

Figure 9. Calculated hydrogen sulfide odour threshold concentrations based on dilution-to-threshold (D/T) values observed at hydrogen sulfide chamber concentrations from 0-45-ppb.

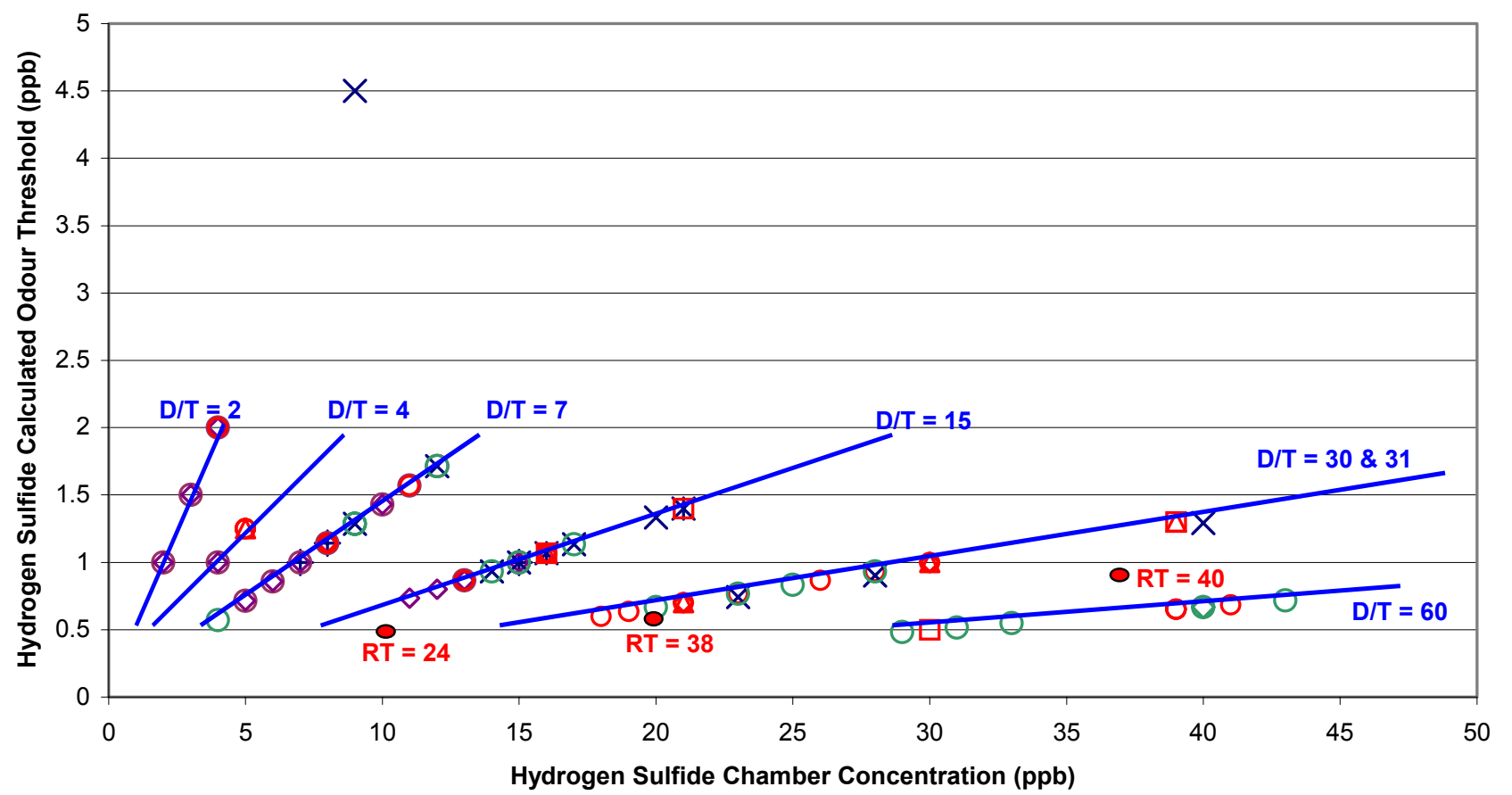

Figure 10. Trendlines for specific dilution-to-threshold (D/T) positions available on commercial field olfactometers relating the calculated hydrogen sulfide odour threshold concentrations to the hydrogen sulfide chamber concentrations from 0-45-ppb. Calculated recognition threshold (RT) values are shown for three odorous air samples collected from the test chamber which were evaluated by laboratory olfactometry following ASTM International E679 and EN13725. 
The Boelens Aroma Chemical Information Service publication titled, "Compilation of Odour Threshold Values in Air and Water" has documented odour thresholds of $\mathrm{H}_{2} \mathrm{~S}$ varying from as low as $0.07 \mathrm{ppb}$ to as high as $3.5 \mathrm{ppm}$ (3,500 ppb) (van Gemert 1999). The data compiled from literature published in the 1980's show these thresholds ranging from $0.5-5 \mathrm{ppb}$. These thresholds were not completely defined as detection or recognition thresholds by their original sources.

In 2000, St. Croix Sensory conducted a research project, funded by the Sacramento Regional County Sanitation District, to determine the odour threshold of hydrogen sulfide using odour testing standards ASTM International E679 and EN13725. During this project, the detection threshold of hydrogen sulfide was found to range from $0.4-1.0$ $\mathrm{ppb}$ and the recognition threshold was found to range from $0.5-2.25 \mathrm{ppb}$.

These published threshold values are comparable to those found in this current study with field olfactometers.

\section{Comparison of Field Olfactometer to Laboratory Olfactometer Results}

During trial \#3, three grab air samples were collected in Tedlar bags for analysis in the odour laboratory at St. Croix Sensory following ASTM International E679 and EN13725. Figure 10 plots the results of the laboratory olfactometer testing based on the calculated odour recognition threshold of hydrogen sulfide (large red circles). These results ranged from $0.45-0.9 \mathrm{ppb}$.

\section{CONCLUSIONS}

A standard method for measuring and quantifying odour in the ambient air utilizes a portable odour detecting and measuring device known as a field olfactometer. The field olfactometer dynamically dilutes the ambient air with carbon-filtered air in distinct dilution ratios known as dilution-to-threshold dilution factors (D/T's).

For this study, a controlled environmental chamber was utilized with hydrogen sulfide as the known test odorant. Test operators entered the chamber to measure the D/T value of the odour as the hydrogen sulfide concentration increased. D/T values were measured by one Scentometer (Barneby Sutcliffe Corp.) user and four Nasal Ranger Field Olfactometer (St. Croix Sensory, Inc.) users. Odorous air samples were collected from the chamber and evaluated by laboratory olfactometry following ASTM International E679 and EN13725. Threshold results were compared to the results obtained by the field olfactometer observations.

During the study, no significant difference was found between results obtained by the one Scentometer user and the four Nasal Ranger users. Furthermore, there was also no significant difference found between results obtained by the four different Nasal Ranger users.

Dilution-to-threshold values were correlated to hydrogen sulfide concentrations in the environmental chamber. The following ranges of results were found: 
2-4 $\mathrm{ppb} \mathrm{H}_{2} \mathrm{~S}$ yields a D/T of 2

$>4-5 \mathrm{ppb} \mathrm{H}_{2} \mathrm{~S}$ yields a $\mathrm{D} / \mathrm{T}$ of 4

$>$ 4-11 ppb $\mathrm{H}_{2} \mathrm{~S}$ yields a D/T of 7

$>11-17 \mathrm{ppb}_{2} \mathrm{~S}$ yields a D/T of 15

$>17-28 \mathrm{ppb} \mathrm{H}_{2} \mathrm{~S}$ yields a D/T of 30

$>28-40+\mathrm{ppb} \mathrm{H}_{2} \mathrm{~S}$ yields a D/T of 60

The $\mathrm{D} / \mathrm{T}$ results obtained by the field olfactometer observations were used to calculate hydrogen sulfide thresholds for the users. Calculated $\mathrm{H}_{2} \mathrm{~S}$ thresholds were found to range from $0.5-2.0 \mathrm{ppb}$. $90 \%$ of all values were in the range of $0.5-1.5 \mathrm{ppb}$. The results of laboratory olfactometry in this study yielded recognition thresholds of 0.45-0.9 ppb.

The threshold values obtained by field and laboratory olfactometry are consistent with published thresholds for hydrogen sulfide, as well as previous research conducted at St. Croix Sensory.

The results from this study provide users of field olfactometers a point of reference for the $\mathrm{D} / \mathrm{T}$ values. The correlation of $\mathrm{D} / \mathrm{T}$ values with hydrogen sulfide allows users to roughly estimate hydrogen sulfide concentrations based on $\mathrm{D} / \mathrm{T}$ values observed in the ambient air.

\section{REFERENCES}

American Industrial Hygiene Association - AIHA (1989), Odor Thresholds for Chemicals with Established Occupational Health Standards. Akron, OH, USA.

ASTM International (1997), Standard Practice for Determination of Odor and Taste Threshold by a Forced-Choice Ascending Concentration Series Method of Limits, E67991(97), Philadelphia, PA, USA.

Committee for European Normalization (CEN) (2003), Air Quality - Determination of Odour Concentration by Dynamic Olfactometry, Brussels, Belgium.

Huey N.A., Broering L.C., Jutze G.A., and Gruber C.W. (1960). Objective Odor Pollution Control Investigations. J. Air Pollution Control Assoc., 10(6), 441-444.

Water Environment Federation (WEF) and the American Society of Civil Engineers (1995), WEF Manual of Practice No. 22 (MOP-22): Odor Control in Wastewater Treatment Plants, Alexandria, VA, USA.

Van Gemert, L.J. (1999), Compilation of Odour Threshold Values in Air and Water. TNO Nutrition and Food Research Institute, Boelens Aroma Chemical Information Service (BACIS), The Netherlands. 